\title{
The Application and Effect Evaluation of Project Information Portal Based on Cloud Model
}

\author{
Hongqing Zhang \\ School of Economics and Management \\ North China Electric Power University \\ Beijing, China \\ 18811376331@163.com
}

\begin{abstract}
This paper introducesthe advantages and its implementation of project information portal and establishes evaluation index system according to the characteristics of the PIP implementation. This paper proposes the cloud model to evaluate PIP implementation effects and uses an example to illustrate the application of cloud model through the matlab5.0 software. Cloud model can convert the qualitative description to quantitative values, fully considering the influence of the fuzzy and random factors in the evaluation process. This method has strong practicability and maneuverability and provides the new way for the PIP implementation effect evaluation.
\end{abstract}

Keywords-component; project information portal; cloud model; effect evaluation

\section{INTRODUCTION}

In the engineering construction process, the effectiveness of information communication is an important factor in successful project implementation. The traditional way of information communication exist the following problems such as the long transmission time,high cost long transmission path and complex hierarchy. This kind of parallel works has high requirements for resources sharing and transmission of the information[1].Project information portal (hereinafter referred to as "PIP") is proposed for the problems.

PIP is a forefront research of the engineering management informatization based on project theme website and project extranet.PIP is a single entry [2] that provides a personalized project information on the Internet platform for the project participants, which based on the centralized storage and management of information and knowledge for the project participants in project implementation process.

\section{Advantages ANALYsis Of ApPlying PiP IN CONSTRUCTION PROJECT}

Information management based on PIP realizes the digitization in each process.Compared with the traditional way on creating information process, PIP just includes only one step which is the creation of digital information. It saves time and cost and improves the accuracy of creating information.In the process of dealing information,information processing based on PIP streamlines some personal segments and greatly shortens the information processing time[3].The information transmission based on PIP has the great superiority on saving time and cost aspects as shown in Table 1.

TABLE I. THE COMPARISON OF INFORMATION TRANSFER PROCESS BETWEEN TRADITIONAL WAY AND PIP

\begin{tabular}{|c|c|c|}
\hline \multirow{2}{*}{$\begin{array}{c}\text { The } \\
\text { Contrast } \\
\text { Item }\end{array}$} & \multicolumn{2}{|c|}{ The Way of Information Management } \\
\hline & Traditional way & $P I P$ \\
\hline $\begin{array}{l}\text { transfer } \\
\text { mode }\end{array}$ & $\begin{array}{l}\text { Staffs use fax, mail and } \\
\text { express mail to send all kinds } \\
\text { of documents to the project } \\
\text { participants. }\end{array}$ & $\begin{array}{l}\text { Participants get their } \\
\text { own authority within the } \\
\text { scope of the information } \\
\text { through the PIP system } \\
\text { login. }\end{array}$ \\
\hline $\begin{array}{l}\text { recording } \\
\text { way }\end{array}$ & $\begin{array}{l}\text { Staffs sign for receiving and } \\
\text { dispatching the document. }\end{array}$ & $\begin{array}{l}\text { PIP system does the } \\
\text { records . }\end{array}$ \\
\hline time & It takes much time. & $\begin{array}{l}\text { The Participants upload } \\
\text { and download from } \\
\text { thesystem which has } \\
\text { thehigh efficiency. }\end{array}$ \\
\hline cost & $\begin{array}{l}\text { It takes labor charges,paper } \\
\text { cost and postal fee. }\end{array}$ & It reduces expenses. \\
\hline
\end{tabular}

\section{THE PIP IMPLEMENTATION IN CONSTRUCTION PROJECT MANAGEMENT}

Thissection researches on the process of PIP implementation in the construction project. Draw lessons from international advanced experience and promote the PIP implementation process in China.

\section{A. The Information Sharing of PIP Implementation}

The PIP information content is the collection of the share information and the common project information of the project participants.From the perspective of time,PIP information content is not the simple accumulation ofeach implementation stage,but sharing information accumulation[4]as shown in in figure 1.

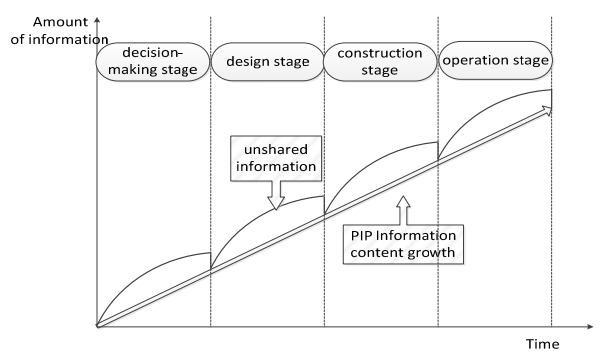

FIGURE I. INFORMATION SHARING OF PIP 


\section{B. The Implementation Process of PIP}

The implementation process of PIP is the key to the success application. It is the main steps to promote the organic combination of information technology and engineering project management. Take the directly purchase mode as an example to illustrate the implementation of PIP.

1) Early-stage preparations. Make the detailed investigation to the requirement of PIP owner,and try to meet the personalized needs of owner.At the same time,we need to make a good communication with the parties involved and meet the user requirements of all parties concerned.

2) Implementary plan. In this stage, we analysis the project breakdown structure, project information organizations and management, establish a document template analysis work process to carry out the corresponding interface design.

3) Installation configurations. Now the application uses ASP model,namely software provider is responsible for establishing and maintaining the platform server. Owners only need to rent the software provider's software and hardware platform.

4) Secondary development. We put the system into trial operation through simulating the actual situation to find some place which is not conformity with the practical engineering. Software vendor make the secondary development[5].

5) Overall implementation. After all testing and commissioning,we take full implementation of PIP in the engineering project.

6) Evaluate improvements. We need regularly to assess and check the application of PIP.It is aimed at discovering the change and the insufficiency.We can make dynamic control and improve continuously.

\section{PIP IMPLEMENTATION EFFECT EVALUATION BASED ON CLOUd MODEL}

\section{A. Cloud Model Introduction}

Cloud model is a model of the uncertainty transition between a linguistic term of a qualitative concept and its quantitative numerical representation. Given a qualitative concept $T$ defined over a universe of discourse $U$, let $x \in U$ is a random instantiation of the concept $\mathrm{T}$ and $\mu \mathrm{T}(\mathrm{x}) \in[0,1]$ is the certainty degree of $\mathrm{x}$ belonging to $\mathrm{T}$, which corresponds to a random number with a steady tendency. Then, the distribution of $\mathrm{x}$ in the universe $\mathrm{U}$ can be defined as acloud and $\mathrm{x}$ can be called as a cloud drop[6].

The cloud model has three numerical characteristics,expected valued ( Ex ) ,Entropy ( En ) and Hyper-Entropy ( $\mathrm{He}$ ), which integrates the fuzziness and randomness of spatial concepts in a unified way[7].

- Ex is the mathematical expectation of the cloud drops belonging to a concept in theuniversal.
- En is a measure of the concept coverage, namely a measure of the spatial fuzziness, which indicates how many elements cloud be accepted to the spatial linguistic concept.

- He is a measure of the dispersion on the cloud drops, which can also be considered as the entropy of En.

\section{B. Cloud Generators}

Cloud model realizes the concept of qualitative and quantitative data transformation through the cloud generator. The generation algorithm of cloud model curing with hardware or software modular is the cloud generator (cloud generator, referred to as CG).Cloud generator mainly includestwo types that are forward andbackward cloud generator.

1) Forward cloud generator. The forward cloud generator is taking the cloud characteristics $(\mathrm{Ex}, \mathrm{En}, \mathrm{He})$ to produce cloud drops, which converts qualitative linguistic value to quantitative data called forward cloud generator.The algorithm in detail is:

a) Produce a normally distributed random number $E n_{i}$ with mean En and standard deviation $\mathrm{He}^{2}$ andremember to $\mathrm{En}_{\mathrm{i}}$ $=\operatorname{NORM}\left(\mathrm{En}_{\mathrm{i}}, \mathrm{He}^{2}\right)$.

b) Produce a normally distributed random number $x_{i}$ with mean $E x$ and standard deviation $E n_{i}^{2}$ and remember to $\mathrm{x}_{\mathrm{i}}=\operatorname{NORM}\left(\mathrm{Ex}, \mathrm{En}_{\mathrm{i}}^{2}\right)$.

c) Calculate $\mathrm{y}=\mathrm{e}^{-\frac{(x-E x)^{2}}{2\left(E n_{\mathrm{i}}\right)^{2}}}$

d) Repeat step a-c until N cloud drops are generated.

2) Backward cloud generator. The backward cloud generator is that the algorithms which produced three numerical characteristics of qualitative language features giving a set of two-dimensional point cloud $\operatorname{drops}\left(\mathrm{x}_{\mathrm{i}}, \mu_{\mathrm{i}}\right)$ according with normal distribution regularity. The algorithm of the backward cloud generator includes two types. One contains the uncertainty information, the other one does not contain uncertainty information.Qualitative evaluation language is difficult to determine the uncertainty information, so this paper takes the algorithm which does not contain the uncertainty information. The algorithmin detail is:

a) Produce Calcuate the mean value andsample variance of $x_{i}(i=1, \cdots, N)$

$$
\begin{gathered}
\bar{X}=\frac{1}{N} \sum_{i=1}^{N} X_{i}(2) \\
S^{2}=\frac{1}{N-1} \sum_{i=1}^{N}\left(x_{i}-\bar{X}\right)
\end{gathered}
$$

b) Calculate the three numerical characteristics

$$
\begin{gathered}
E_{X}=\bar{x}(4) \\
E n=\sqrt{\frac{\pi}{2}} \times \frac{1}{N} \sum_{i=1}^{N}\left|x_{i}-\bar{x}\right| \\
H e=\sqrt{\left|S^{2}-E n^{2}\right|}
\end{gathered}
$$




\section{Building the Cloud Model by an Example}

This article selects a construction unit using PIP as the evaluation sample. Apply the cloud model to evaluate the PIPimplementation effects by 10 experts who are the enterprise policymakers and project managers.

1) Building the index system of PIP implement effect evaluation. This paper uses the experience method to build the PIP effect evaluation index system according the comprehensive evaluation target characteristics and the change of company operation after PIP implementation. The index systemis shown in table 2 .

TABLE II. THE INDEX SYSTEM OF PIP IMPLEMENT EFFECT EVALUATION

\begin{tabular}{|c|c|c|}
\hline Object Set & $\begin{array}{l}\text { Major factor Set } \\
\text { (3 First-level } \\
\text { Indexes) }\end{array}$ & $\begin{array}{c}\text { Sub-factor set } \\
\text { (9 Second-level Indexes) }\end{array}$ \\
\hline \multirow{9}{*}{$\begin{array}{l}\text { PIP } \\
\text { implement } \\
\text { effect } \\
\text { evaluation }\end{array}$} & \multirow{3}{*}{$\begin{array}{l}\text { The financial } \\
\text { effects }\end{array}$} & Degree of cost reduction \\
\hline & & Degree of profit increase \\
\hline & & Speed of capital turnover \\
\hline & \multirow{3}{*}{$\begin{array}{c}\text { The competition } \\
\text { effect }\end{array}$} & Corporate profile \\
\hline & & The market share \\
\hline & & Themarket expanding speed \\
\hline & \multirow{3}{*}{$\begin{array}{l}\text { Enterprise interior } \\
\quad \text { ability }\end{array}$} & Financing ability \\
\hline & & Information degree \\
\hline & & The management level \\
\hline
\end{tabular}

2) Building the cloud model of evaluation set. The evaluation set is the selection range of evaluation results after the evaluation. This paper uses the golden sectionmodel driven method, set the evaluation standard of cloud model, namely the cloud scale. The qualitative linguistic valuescope of evaluation sets is $[0,10]$.The smaller En and He is supplied by 0.618 times between adjacent clouds according the golden sectionmethod. He is 0.05 made by experts. We can get five language qualitative linguistic values in table 3 .

TABLE III. The Cloud Model of Evaluation Sets

\begin{tabular}{|c|c|}
\hline Five Language value & Cloud model(Ex,En,He) \\
\hline poor & $(0,1.029,0.131)$ \\
\hline Worse & $(3.09,0.636,0.081)$ \\
\hline ordinary & $(5,0.393,0.05)$ \\
\hline fine & $(6.91,0.636,0.081)$ \\
\hline very well & $(10,1.029,0.131)$ \\
\hline
\end{tabular}

Apply the forward cloud generator to paint clouds through matlab5.0. The linguistic language value with three numerical

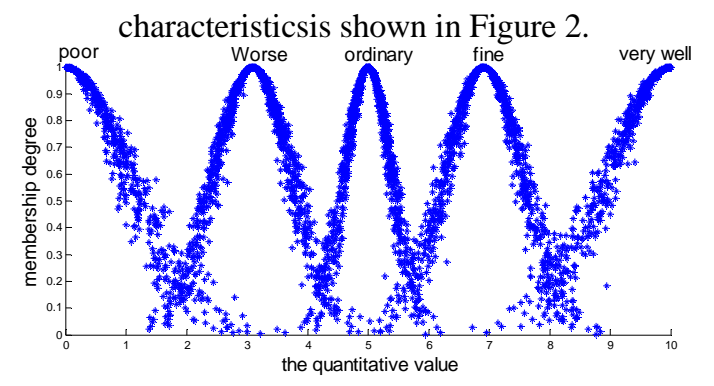

FIGURE II. THE CLOUD OF THE LINGUISTIC LANGUAGE

3) Calculate the weight Indexs. This paper adopts the Analytic Hierarchy Process(AHP) to establish the judgment matrix and solve the weights. AHP is no longer introduced in detail, results as shown in table 4.

TABLE IV. THE WEIGHTS OF INDEXS

\begin{tabular}{|c|c|}
\hline Sub-factor set & weights \\
\hline Degree of cost reduction & 0.1023 \\
\hline Degree of profit increase & 0.1355 \\
\hline Speed of capital turnover & 0.0836 \\
\hline Corporate profile & 0.1195 \\
\hline The market share & 0.1356 \\
\hline Themarket expanding speed & 0.1128 \\
\hline Financing ability & 0.1100 \\
\hline Information degree & 0.0989 \\
\hline The management level & 0.1017 \\
\hline
\end{tabular}

4) The actual cloud model of Sub-factor set. Provide the questionnaires for engineering staff.The engineering staffgrade for the elements listed questionnaires scores according the actual objective conditions of this engineering Project as shown in table5. Collect the questionnaires and use the backward cloud generator that does not contain uncertainty information to calculate the three numerical characteristics of the index system according the formulas(2)-(6),as shown in table 6 .

5) Comprehensive cloud computing.To get the final evaluation results, we must to make a comprehensive cloud computing after getting the cloud model parameters of the Sub-factor set. Comprehensive cloud computing mainly includes: major factor set and object setcomprehensive cloud computing. Then take the object set comprehensive cloud picture to compare with the cloud picture of evaluation set aimed at getting the evaluation results.

TABLE V. THE QUESTIONNAIRES SCORES OF EXPERTS

\begin{tabular}{|c|c|c|c|c|c|c|c|c|c|c|}
\hline \multirow{2}{*}{ Index } & \multicolumn{10}{|c|}{ Experts } \\
\hline & (1) & (2) & (3) & (4) & (5) & (6) & (7) & (8) & (9) & $(\mathbf{1 0})$ \\
\hline Degree of costreduction & 5 & 5.5 & 4.5 & 5 & 6 & 5 & 6 & 5.5 & 6 & 5.5 \\
\hline Degree of profit increase & 7.5 & 8 & 8.5 & 7 & 7 & 8 & 8.5 & 8 & 7.5 & 8 \\
\hline Speed of capital turnover & 9 & 8.5 & 8 & 8.5 & 9.5 & 8 & 8.5 & 8 & 8.5 & 9 \\
\hline Corporate profile & 7 & 7.5 & 8.5 & 8 & 9 & 7 & 9 & 8 & 7 & 8.5 \\
\hline The market share & 6 & 7.5 & 7 & 6.5 & 7 & 7.5 & 8 & 6.5 & 6.5 & 7 \\
\hline Themarket expanding speed & 8 & 8.5 & 8 & 7 & 8 & 8 & 8.5 & 7.5 & 7.5 & 8.5 \\
\hline Financing ability & 4 & 5 & 6 & 5 & 5.5 & 6.5 & 6.5 & 6 & 5.5 & 6 \\
\hline Informationdegree & 9 & 9.5 & 8.5 & 8 & 9.5 & 9 & 7.5 & 8 & 7 & 9 \\
\hline The management level & 8 & 8.5 & 9 & 7.5 & 8 & 8.5 & 7 & 8 & 8.5 & 8 \\
\hline
\end{tabular}


TABLE VI. The CloudModelofSub-FActor SET IN Actual

\begin{tabular}{|c|c|}
\hline Sub-factor set & $\begin{array}{c}\text { Cloud model } \\
\text { (Ex,En,He) }\end{array}$ \\
\hline Degree of cost reduction & $(5.4,0.526,0.102)$ \\
\hline Degree of profit increase & $(7.8,0.551,0.123)$ \\
\hline Speed of capital turnover & $(8.55,0.464,0.179)$ \\
\hline Corporate profile & $(7.95,0.827,0.219)$ \\
\hline The market share & $(6.95,0.577,0.161)$ \\
\hline Themarket expanding speed & $(7.95,0.464,0.179)$ \\
\hline Financing ability & $(5.6,3.133,1.508)$ \\
\hline Information degree & $(8.5,0.978,0.236)$ \\
\hline The management level & $(8.1,0.526,0.212)$ \\
\hline
\end{tabular}

Suppose there are many clouds which are cloud1 $\left(\mathrm{Ex}_{1}, \mathrm{En}_{1}, \mathrm{He}_{1}\right) \quad$,cloud2 $\left(\mathrm{Ex}_{2}, \mathrm{En}_{2}, \mathrm{He}_{2}\right) \quad \ldots \quad$ and cloudn $\left(\mathrm{Ex}_{\mathrm{n}}, \mathrm{En}_{\mathrm{n}}, \mathrm{He}_{\mathrm{n}}\right)$. The weights of the clouds are $A_{1}, A_{2}, \cdots, A_{n}$. The algorithm of comprehensive cloud [8]in detail is:

$$
\begin{aligned}
E_{X} & =\frac{E X_{1} A_{1}+E X_{2} A_{2}+\ldots+E X_{n} A_{n}}{A_{1}+A_{2}+\ldots+A_{n}} \\
E n= & \frac{A_{1}^{2}}{A_{1}^{2}+A_{2}^{2}+\ldots+A_{\mathrm{n}}^{2}} * E_{n_{1}}+\frac{A_{2}^{2}}{A_{1}^{2}+A_{2}^{2}+\ldots+A_{\mathrm{n}}^{2}} * E n_{2} \\
& +\ldots+\frac{A_{n}^{2}}{A_{1}^{2}+A_{2}^{2}+\ldots+A_{\mathrm{n}}^{2}} * \mathrm{En}_{n}
\end{aligned}
$$

$$
\begin{aligned}
H e= & \frac{A_{1}^{2}}{A_{1}^{2}+A_{2}^{2}+\ldots+A_{\mathrm{n}}^{2}} * H_{e_{1}}+\frac{A_{2}^{2}}{A_{1}^{2}+A_{2}^{2}+\ldots+A_{\mathrm{n}}^{2}} * \mathrm{He}_{2} \\
& +\ldots+\frac{A_{n}^{2}}{A_{1}^{2}+A_{2}^{2}+\ldots+A_{\mathrm{n}}^{2}} * \mathrm{He}_{n}
\end{aligned}
$$

According the formulas (7) - (9),we can get the cloud model of object set in table 7.Apply the forward cloud generator to paint comprehensive clouds through matlab5.0 as shown in figure 3.

TABLE VII. THE CLOUdCOMPREHENSIVEMODEL

\begin{tabular}{|c|c|c|c|}
\hline Object Set & (Ex,En,He) & $\begin{array}{c}\text { Major factor } \\
\text { Set }\end{array}$ & (Ex,En,He) \\
\hline & & $\begin{array}{c}\text { The financial } \\
\text { effects }\end{array}$ & $(7.231,0.527,0.128)$ \\
\cline { 3 - 4 } $\begin{array}{c}\text { PIP } \\
\text { implement } \\
\text { effect } \\
\text { evaluation }\end{array}$ & $(7.394,0.887,0.317)$ & $\begin{array}{c}\text { The } \\
\text { competition } \\
\text { effect }\end{array}$ & $(7.581,0.624,0.185)$ \\
\cline { 3 - 4 } & & $\begin{array}{c}\text { Enterprise } \\
\text { interior } \\
\text { ability }\end{array}$ & $(7.342,1.642,0.706)$ \\
\hline
\end{tabular}

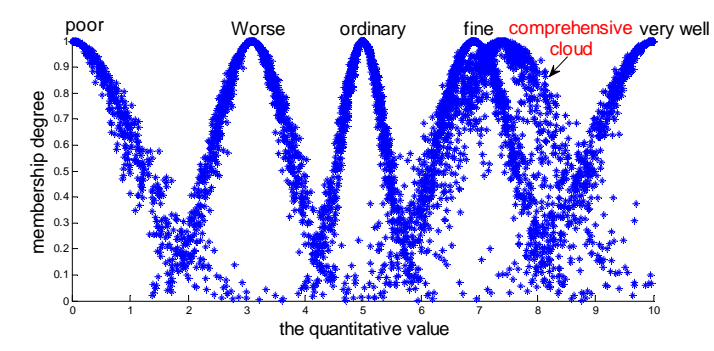

FIGURE III. THE COMPARE BEWTEEN THE COMPREHENSIVE CLOUD AND EVALUATION SET CLOUD

6) Results analysis. The figure 5 shows that most of the cloud drops between fine and well. We can get the evaluation results that the PIP implementation effect is good.

\section{CONCLUSION}

PIP is the important value-added tool for investment project, construction project which is the important symbol of the current project management informationization. Applying the cloud model solved the evaluationproblem that turnssome qualitative description to quantitative evaluation index. It fully considered the influence of fuzzy factors and random factors in the evaluation process.Applying the cloud model to the PIP implementation effect assessment is an effective attempt.

\section{REFERENCES}

[1] Michel Thiry. "Combining value and project management into an effective programme management model," International Journal of Project Management,2002, pp.221-227.

[2] Weidong Yang, Anqi Niu, Xiaolei LV and Haixin Fei, “The study of the problems and countermeasures in the application of project information portal, " Construction \& Design for Project. 2014, pp.150-152.

[3] Yujing Wang, "Research on the project information management based on project information portal,”Construction Management Modernization. 2007, pp.44-47.

[4] Yue Zhou, "The establishment and implementation of project information portal platform, ” Science Information. 2007,pp. 310-311.

[5] Wei Guo,“The application analysis of PIP in construction engineering project management,"Chongqing Techonl Business Univ. vol. 26, Apr.2009, pp.168-169.

[6] Bo Jin,Yong Wang, Zhenyan Liu, Jingfeng Xue, “A Trust Model Based on Cloud Model and BayesianNetworks,”Procedia Environmental Sciences.2011,pp.452-459.6.

[7] Shuliang Wang, Deren Li, Wenzhong Shi , Deyi Li,Xinzhou Wang, “Cloud Model-Based Spatial Data Mining,"Geographic Information Sciences.vol 9,2003,pp.60-70.

[8] Yunlong,“Aerated Concrete Masonry Infilled Wall Crack Control and Quality Evaluation Based on Cloud Model,"Southwest Petroleum University,2014,PP.54-55. 